\title{
Subacute encephalitis in an adult associated with necrotising myelitis and results of animal inoculation experiments
}

\author{
A. M. G. CAMPBELl, R. M. NORMAN, AND R. J. SANDRY \\ From the Burden Neuropathological Laboratory, Frenchay Hospital, \\ Bristol, and the Bristol Royal Infirmary
}

Sporadic subacute encephalitis of unknown aetiology is a rare condition in adults. A few cases can be assigned to the category of van Bogaert's subacute sclerosing leucoencephalitis, for example, those of Wender (1957) and of Krücke (1957 case 9), but this remains essentially a disease of infancy and childhood. The subacute cases of Brierley, Corsellis, Hierons, and Nevin (1960), which belonged to an older age group, were considered to represent a distinct morphological type because of the predominant involvement of the limbic areas. Three of Pette and Döring's (1939) cases of 'panencephalitis' were in adults, but whether this variety can be clearly separated pathologically from subacute sclerosing leucoencephalitis has been the subject of inconclusive discussion (Macken and Lhermitte, 1950; van Bogaert, 1952, 1958). More than 70 detailed reports of cases of subacute sclerosing leucoencephalitis are now available and it is evident that while the clinical features are usually remarkably uniform there may be a great range of variation in the overall neuropathological picture (van Bogaert, 1957). Because of this wide spectrum of pathological change many recent authors no longer attempt a finer subdivision of these encephalitides of unknown aetiology and prefer a broad classification. Thus Lorand, Nagy, and Tariska (1962) group together under the name 'subacute progressive panencephalitis' the inclusion body encephalitis of Dawson, van Bogaert's subacute sclerosing leucoencephalitis, and cases of the Pette-Döring type. This point of view has been clearly put by Tariska (1961) who writes: 'One extreme of the pathological picture is characterized by the predominance of the inflammatory process in the white matter, i.e., van Bogaert type, the other by the predominance in the grey matter, i.e., Pette-Döring type. Both extremes may be with or without inclusion bodies in the nerve or oligodendroglial cells, though most of the cases are mixed.'
The present communication concerns a woman of 40 whose progressive encephalitis lasted 10 months. There were two remarkable features. First the spinal cord showed extensive destruction of myelinated fibres accompanied by more intense inflammatory changes than have yet been reported in association with encephalitis. Secondly, intracerebral injection of material from the brain and cord into Icelandic sheep has been followed by a severe neurological illness after an interval of two to three years.

\section{CASE REPORT}

Mrs. M., a housewife, aged 38, was admitted to the Bristol Royal Infirmary in August 1959 with a history that in the previous April she had noted attacks of vertical diplopia. In July she showed an increasing weakness and stiffness of the legs. The diplopia persisted and vomiting became a troublesome feature. She gave no history of any previous illness. She had two healthy children aged 17 and 14 years. Her husband, parents, and one sister were fit and well. She had had no contact with infections or toxins of any kind.

General examination was negative. Blood pressure was $120 / 80 \mathrm{~mm}$. $\mathrm{Hg}$. There was nystagmus in both directions and a left external rectus palsy. She had bilateral cerebellar ataxia, and some spasticity of both legs with extensor plantar responses. No sensory changes were detected at this admission.

A blood count was normal and the blood Wassermann reaction was negative. The cerebrospinal fluid was at a pressure of $80 \mathrm{~mm}$. with 25 cells (95\% lymphocytes) and protein $101 \mathrm{mg}$. per $100 \mathrm{ml}$., Lange curve 110000000. Chest and skull radiographs were normal. The Kveim test was negative.

The patient was discharged in September 1959.

She was readmitted in November showing complete left ophthalmoplegia and gross spasticity and cerebellar ataxia. She had now developed signs of posterior column dysfunction with loss of postural and vibration sense in both legs. Pressure of the cerebrospinal fluid was normal. There were 56 cells (95\% lymphocytes) and the protein level was $360 \mathrm{mg}$. per $100 \mathrm{ml}$., Lange curve 433321000 . A 
week later the cells were 70 and the protein was $210 \mathrm{mg}$. An air encephalogram showed atrophy of the brain consistent with encephalitis or disseminated sclerosis. Electrolytes were normal. No L.E. cells were seen in blood films. An electroencephalogram showed abnormal discharges in the left hemisphere and a focal discharge in the left temporo-occipital region.

The patient continued to deteriorate and became fatuous and emotional. She was allowed to return home, but in February 1960 became speechless and comatose, dying suddenly after a week in coma. A fortnight before the onset of coma difficulty in swallowing and bilateral facial weakness had been noted by her husband.

It was obvious that if the diagnosis were that of disseminated sclerosis, this was one of those rare cases with no evidence of any remission, and that the protein level of $100 \mathrm{mg}$. to $300 \mathrm{mg}$. was very high. The disease had always been active and there appeared to be clinical evidence of gross involvement of the cortex and brain-stem. It was not possible to decide on clinical grounds whether this was an atypical case of disseminated sclerosis or of subacute encephalitis. The absence of rythmical myoclonus and of the characteristic E.E.G. were points against the diagnosis of van Bogaert's subacute sclerosing leucoencephalitis. Sarcoidosis was considered unlikely in view of the negative Kveim test.

\section{NECROPSY FINDINGS}

Apart from moderate hypertrophy of the left ventricle of the heart and extensive bronchopneumonia in the left lung, significant changes were found only in the central nervous system.

\section{STUDY OF THE CENTRAL NERVOUS SYSTEM}

MACROSCOPIC The dura, dural venous sinuses, and leptomeninges were normal. The superficial cerebral blood vessels showed moderate uniform engorgement. The brain showed no obvious external abnormality, and limited sections made at once to obtain samples for virological examination revealed only generalized hyperaemia of the white matter. Further sections of the brain made after fixation showed no additional changes to the naked eye. The spinal meninges and blood vessels were normal and the spinal cord showed no obvious external change. Section of the spinal cord made after fixation revealed softening in the region of the posterior columns.

MICROSCOPIC Celloidin, paraffin, and frozen sections, including coronal sections of the cerebral hemispheres, were prepared from representative areas of the brain and spinal cord and stained for nerve cells, axis cylinders, myelin, fibrous neuroglia, $\frac{}{\bar{D}}$ and lipid.

Cerebral cortex Lymphocytic cuffing of veins and microglial proliferation, diffuse or more rarely $\square$ nodular, were seen bilaterally and almost exclusively in the posterior and basal parts of the frontal lobe, $\stackrel{?}{\text { ․ }}$ the insula and walls of the Sylvian fissure, and the temporal lobe. A small part of the right cingulate. gyrus was also involved. The hippocampal gyrus (Fig. 1) was more affected than the cornu Ammonis. The overlying leptomeninges showed lymphocytic infiltration and an occasional cuffed vessel. There $\frac{\bar{c}}{\bar{D}}$ was no detectable neuronal loss, except in two small $\vec{\Phi}$ foci of recent haemorrhage in the right occipital $\varrho$ lobe, where there were no associated inflammatory of changes.

Cerebral white matter A slight diffuse pallor of $\rightarrow$ myelin staining of doubtful significance was present $\vec{\omega}$ in the central parts of the centrum ovale, but this was unaccompanied by fibrous gliosis. The inflammatory changes were slight and consisted in an occasional cuffed vessel and microglial star. Frank demyelination was seen in the right optic radiatiol at its entrance into the calcarine cortex. Fibroo ${ }^{\omega}$ gliosis was present here and also in the terminal o part of the optic radiation of the other side. There was some increase in periventricular glial fibre spreading in from the subependymal region but the ? main part of the centrum ovale did not show gliosis. More marked inflammatory changes were found the hippocampal white matter subjacent to the affected cortex (Fig. 2). In this situation there was fibrous gliosis but no apparent demyelination.

Basal ganglia Heavy perivascular cuffing and proliferation of microglia, sometimes as dense aggregations, were features of both thalami (Fig. 3), mainly in the medial and lateral nuclei where there $\mathbb{Q}_{\infty}$ was some loss of nerve cells and myelinated fibres. Changes of comparable severity were present in the $\frac{0}{3}$ right lateral geniculate body, the nucleus basalis (bilaterally), and the left globus pallidus which showed demyelination, neuronal loss, and occasional figures of neuronophagia. Milder inflammatory changes were seen in the right putamen, and on? both sides in the amygdaloid nucleus, zona incerta, claustrum, and mammillary body.

Brain-stem With the exception of the substantia nigra, encephalitic changes were present throughout the midbrain and medulla (the pons had been $\triangle$ removed for virus studies). The red nuclei were very $\frac{D}{O}$ severely involved (Fig. 4). There was considerable loss of nerve cells in the right inferior olive which N was accompanied by marked loss of hilar fibres.

Cerebellum The central white matter showed diffuse pallor of myelin staining in one lateral lobec 


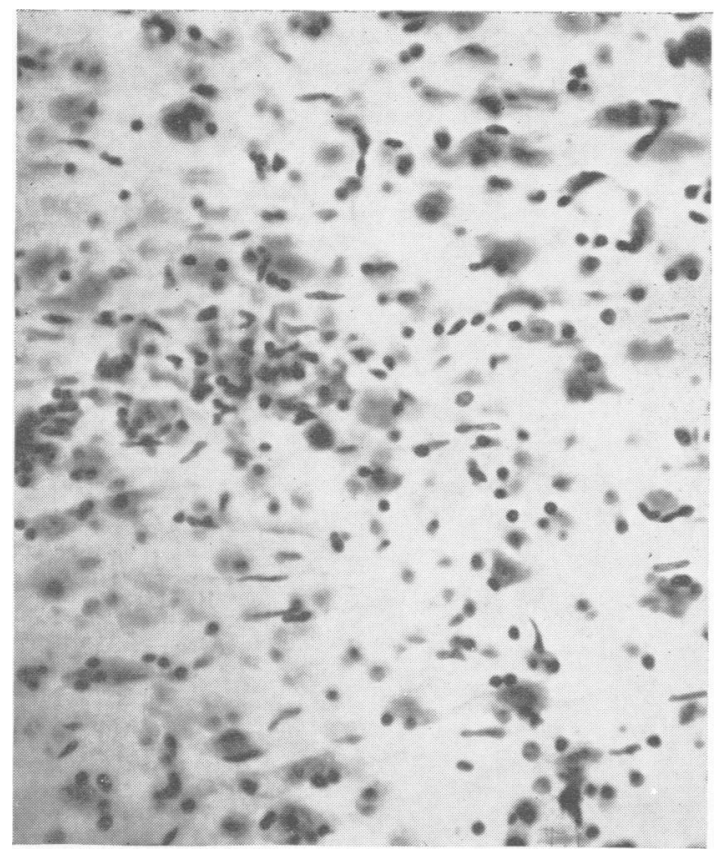

FIG. 1

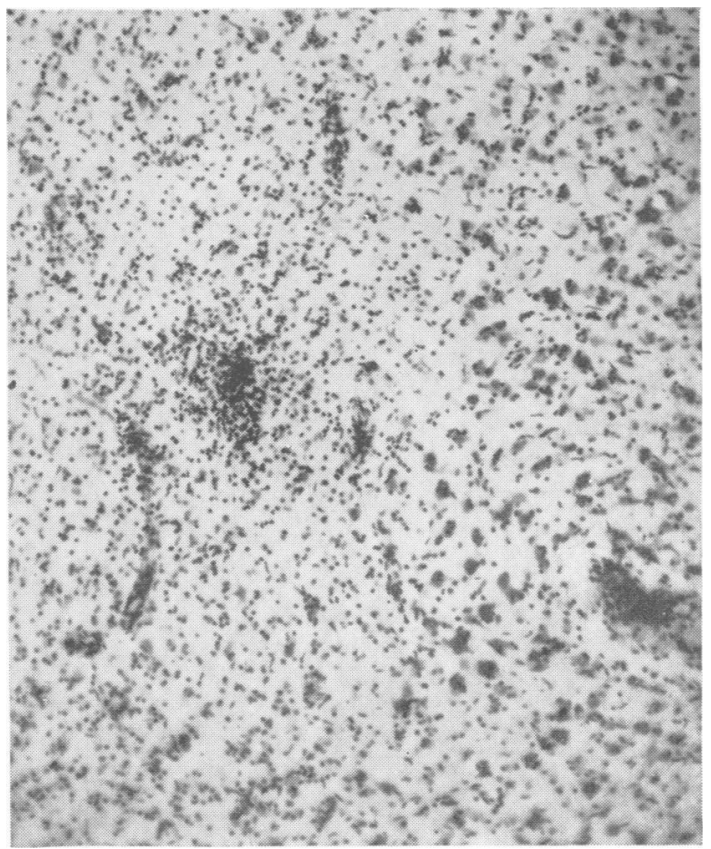

FIG. 2

FIG. 1. Cortex of hippocampal gyrus. Microglial proliferation with numerous rod cells. Carbol azure $\times 280$.

FIG. 2. White matter of hippocampal gyrus showing microglial nodules and lymphocytic cuffing of small vessels. Carbol azure $\times 100$.

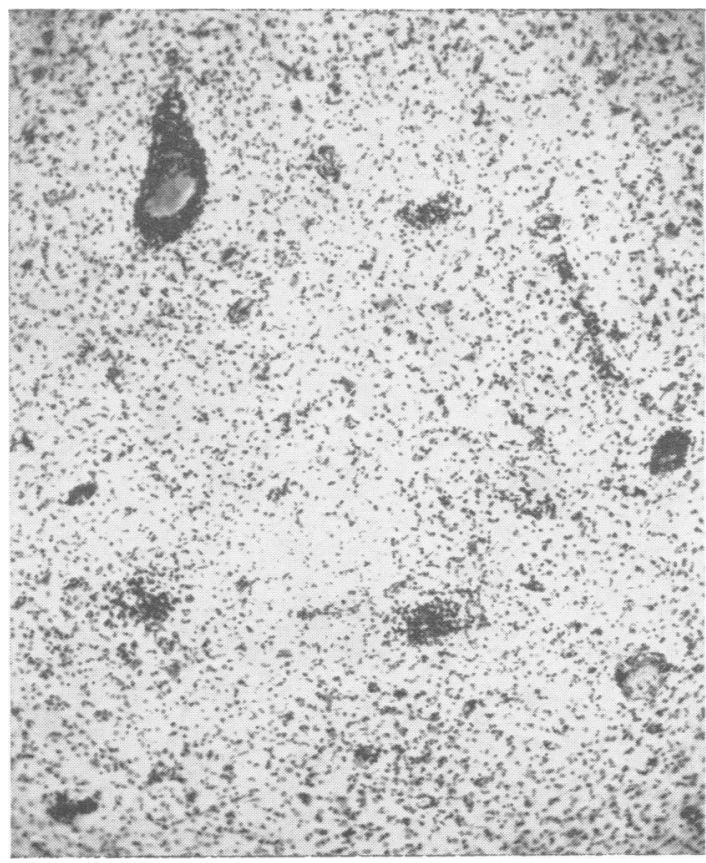

FIG. 3

FIG. 3. Thalamus. Lymphocytic cuffing of vessels, microglial nodules, and diffuse neuronal loss. Carbol azure $\times 75$. FIG. 4. Red nucleus showing encephalitic changes. Carbol azure $\times 100$ 


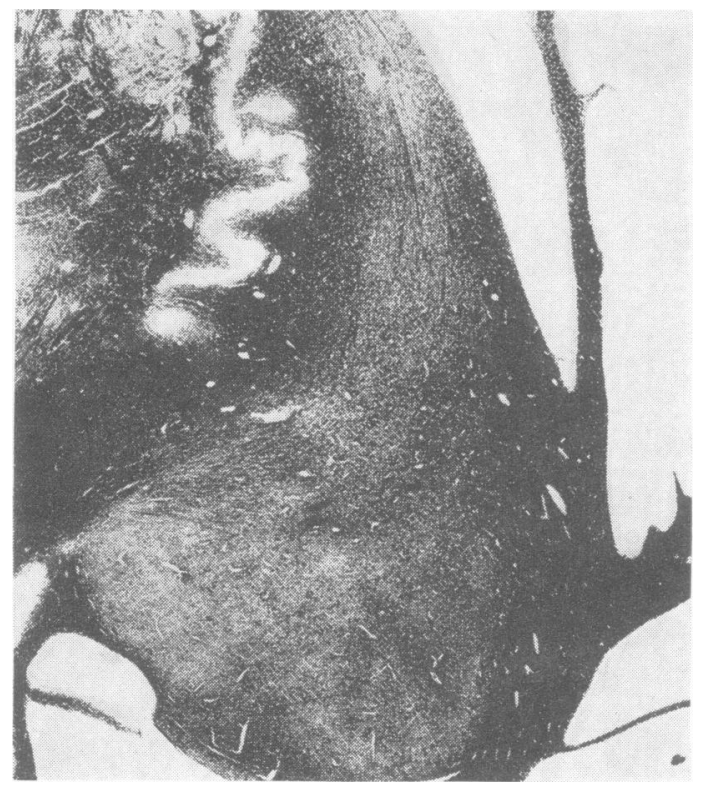

FIG. 5. Cerebellum. Lateral lobe shows loss of myelinated fibres. Frozen. Kultschitsky-Pal $\times 3 \cdot 5$.

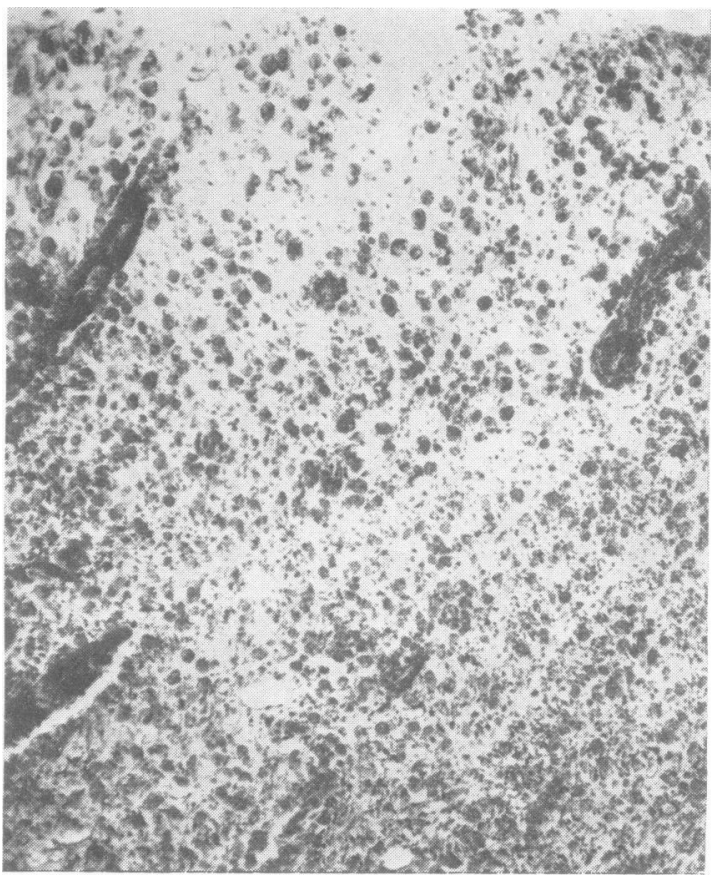

FIG. 9. Fat granule cells in necrotic lateral column of spinal cord. Scharlach $R$ and haematoxylin $\times 70$.

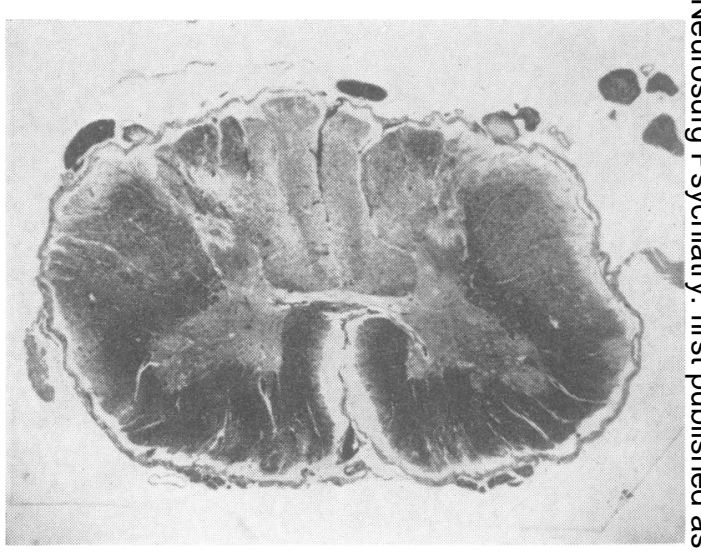

FIG. 6.

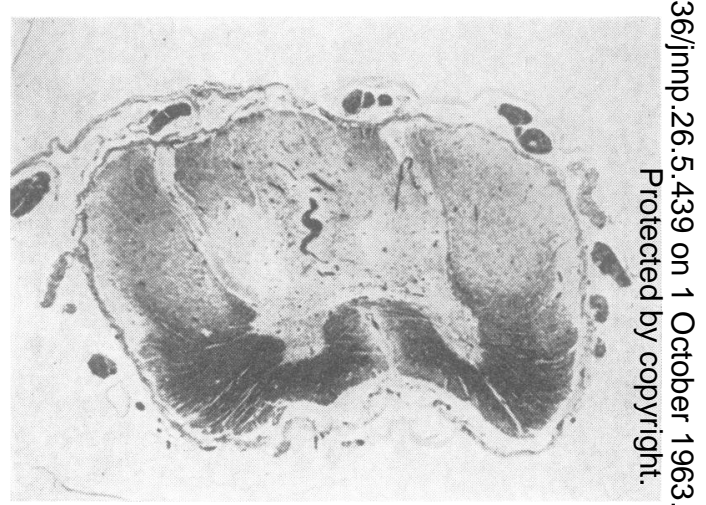

FIG. 7.

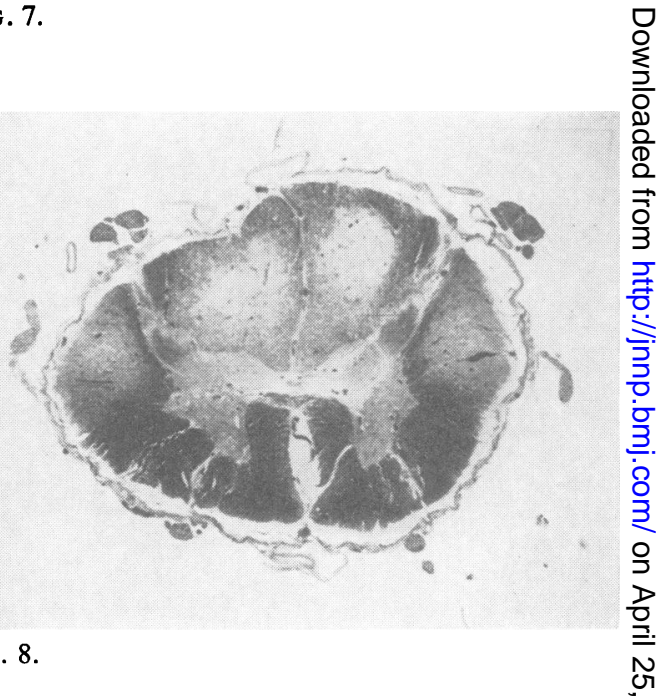

FIG. 8 .

FIGS. 6, 7, and 8. Loss of myelinated axons in the N posterior half of the spinal cord (segments $C 6, T 7$, and $L 1$, N respectively). Heidenhain $\times 7$. 


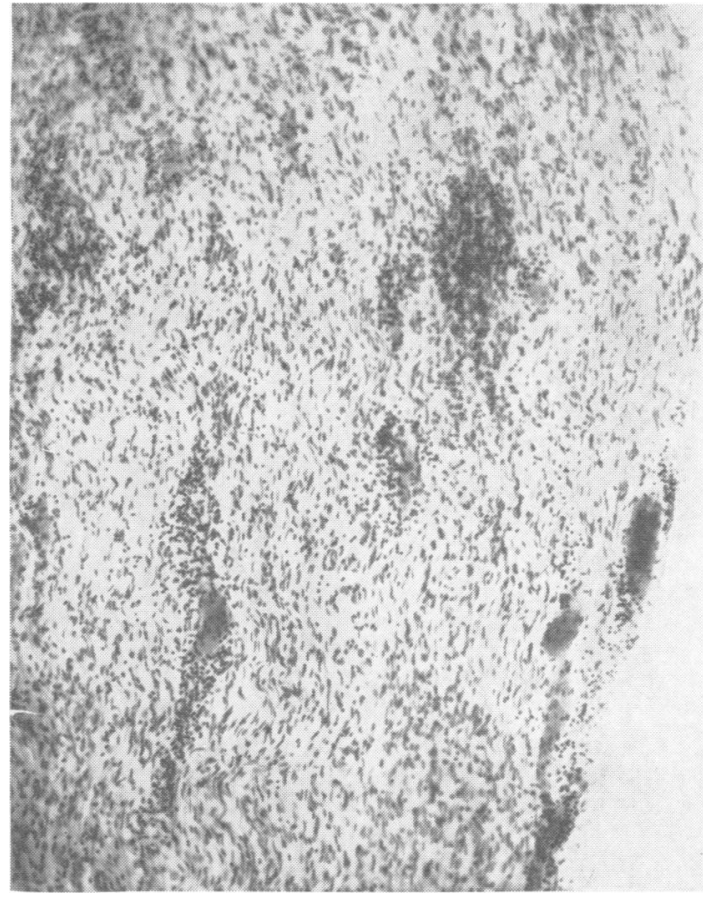

FIG. 10. Nerve root from cauda equina showing lymphocytic cuffing of vessels. Carbol azure $\times 90$.

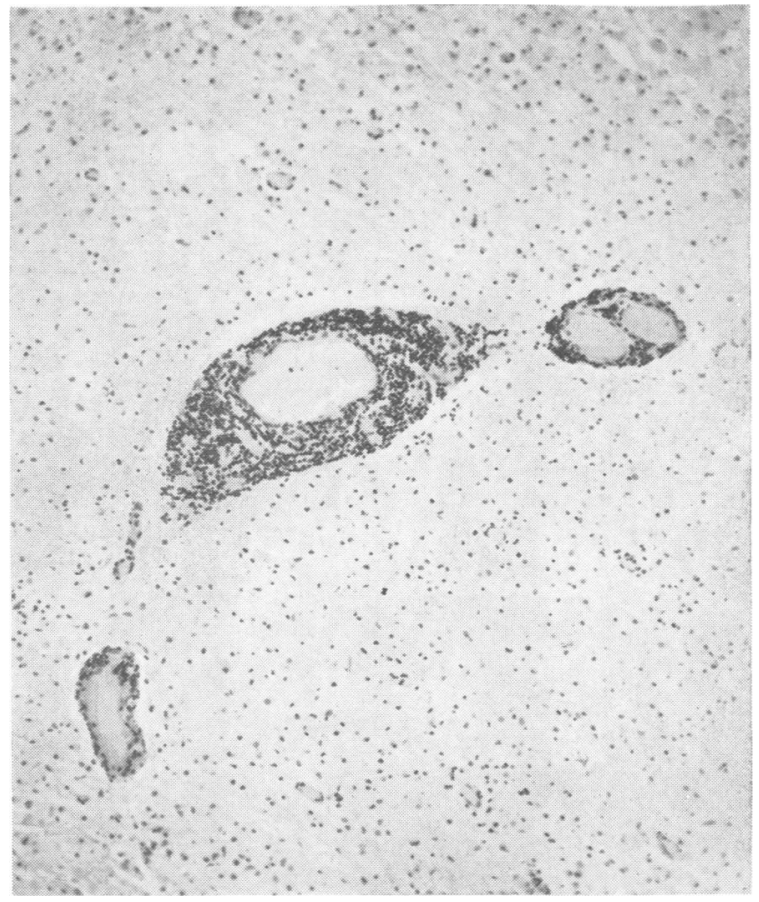

FIG. 11. Lymphocytic cuffing of veins in white matter of spinal cord. Haematoxylin and eosin $\times 86$.

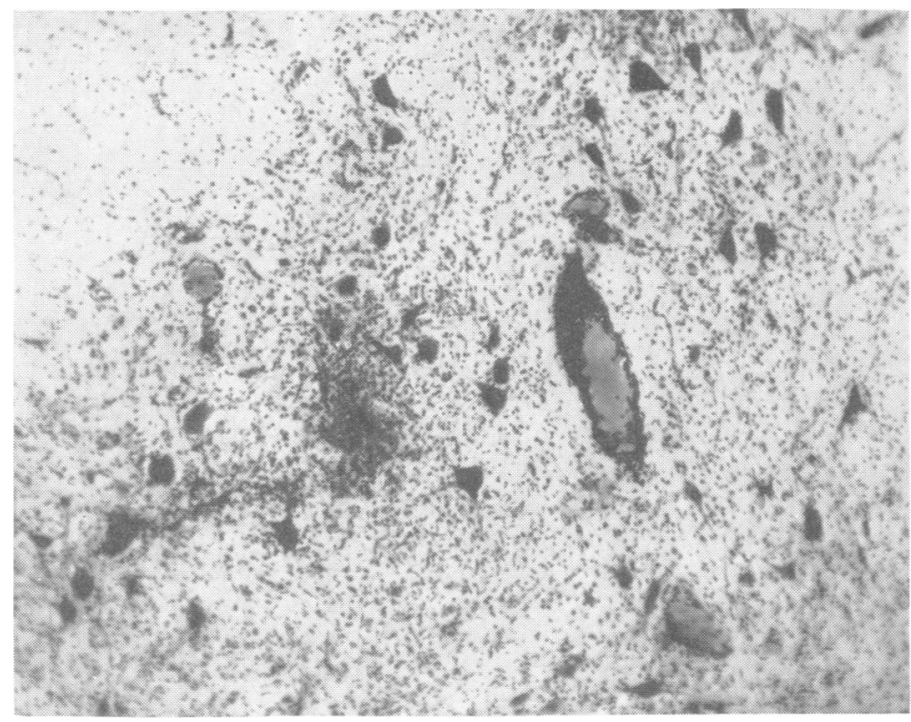

FIG. 12. Anterior horn at C8 level showing inflammatory changes. Carbol azure $\times 75$. 
(Fig. 5) but no lipid breakdown products were seen. Encephalitic changes were slight except in the dentate nucleus where there was patchy microgliosis. There was an increase in glial fibres spreading in from the subependymal tissue. Fibrous gliosis was present in many of the folial cores and also here and there in the subcortical regions, but the cortex itself was normal.

Spinal cord A severe and diffuse loss of myelinated axons was evident in the posterior half of the cord involving the posterior columns, the crossed pyramidal tracts, and the spino-cerebellar tracts (Figs. 6, 7, and 8). The pyramidal tracts in the thoracic cord were more severely affected than in the cervical. The anterior part of the cord did not stain with normal intensity in myelin preparations, the general pallor being particularly evident in the lower thoracic segments where swollen axis cylinders were numerous. There were abundant fat granule cells throughout the degenerated posterior half of the cord (Fig. 9) and a few were seen elsewhere in the marginal zone, which in most segments had an accentuated pallor. There was no demonstrable increase in fibrous neuroglia. Patchy lymphocytic infiltration was present in the leptomeninges, around vessels in the anterior and posterior roots (Fig. 10), in the anterior fissure and posterior septum, and in the white matter of the cord, whether severely demyelinated or not (Fig. 11). Inflammatory changes were especially prominent in the grey matter where heavily cuffed vessels and dense proliferation of microglia were features of many segments (Fig. 12). The nerve cells showed only minor pathological changes. The spinal arteries and veins were not occluded or thickened. No inclusion bodies were found in any part of the brain or cord.

\section{DISCUSSION}

The range of variation is so wide in subacute sclerosing leucoencephalitis that it is possible to match the individual features of the present case with those of undoubted examples of this type of encephalitis. Nevertheless, the overall picture was distinctly atypical, both clinically and pathologically. This was particularly so in the distribution of the telencephalic lesions. Encephalitic changes in the cortex were mainly limited to the hippocampi, insulae, and walls of the Sylvian fissures but were not so severe as those found in the cases of Brierley, Corsellis, Hierons, and Nevin (1960). In the cerebral white matter inflammatory changes were mainly concentrated below the affected grey matter. Unequivocal demyelination was only found below the calcarine cortex of one side, marked fibrous gliosis being present bilaterally in this situation. On the other hand, the minor lesions of the dentate nucleus and cerebellar white matter, and the distribution and severity of the encephalitic changes in the thalamus, on globus pallidus, and brain-stem are typical of sub- $\overrightarrow{0}$ acute sclerosing leucoencephalitis.

The main interest of the case centres upon the severe system-like degenerations in the spinal cord. Once again there are similarities with what has been described in certain examples of subacute sclerosing leucoencephalitis. In some of his cases van Bogaert (1952) had noted gliosis in the posterior columns or pyramidal tracts, with or without pallor of myelin staining. Marked demyelination in the cord was reported by Kalm (1952, case 3) and in the three cases of Martin and Isler (1957). The latter were included in a comprehensive survey of 50 cases of sub- $\$$ acute sclerosing leucoencephalitis made by Guazzi $\vec{O}$ (1961) at the Antwerp symposium on encephalitides. $\overrightarrow{\vec{H}}$ Twenty-seven cords were available for this study. क् Pallor of myelin and gliosis were found in the posterior columns in 14 cases, in the lateral columns in 27 cases, and in the anterior columns in 16 cases. N The dorsal spino-cerebellar tracts were affected in $\dot{v}$ one instance. As in our case it was noted that the direct pyramidal tracts might be spared while th crossed fibres were severely damaged. Dense accif 을 mulations of fat granule cells were seen in two cases. Guazzi was not impressed by the inflammato $\bigcirc$ changes and concluded that the demyelination was o secondary and not associated with a myelitis, thoug $\mathbb{\Phi}$ he admitted the difficulty in reconciling this vie通with the lesions in the afferent fibres. In the present case, however, there were no suprasegmental lesions capable of causing secondary degeneration of the pyramidal tracts. In view of the marked inflammatory changes in both white and grey matter there seems to be no valid objection to regarding the necrotic lesions as those of a true myelitis and an integral part of the infective process present elsewhere in the brain.

RESULTS OF THE ANIMAL INOCULATION EXPERIMENT

As part of a research project planned by one of us (A.M.G.C.) material from the brain and spinal cord of this patient had been injected intracerebrally into four sheep by Dr. Pálsson of the Keldur Institute in southern Iceland. After an interval of about two years two of these animals began to show ataxia, stiff hind limbs, and head nodding. The temperature and appetite were normal. One sheep recovered, while the other rapidly deteriorated and was killed when in extremis. Ten months later a third sheep began to show similar signs and was killed when it became helpless. 


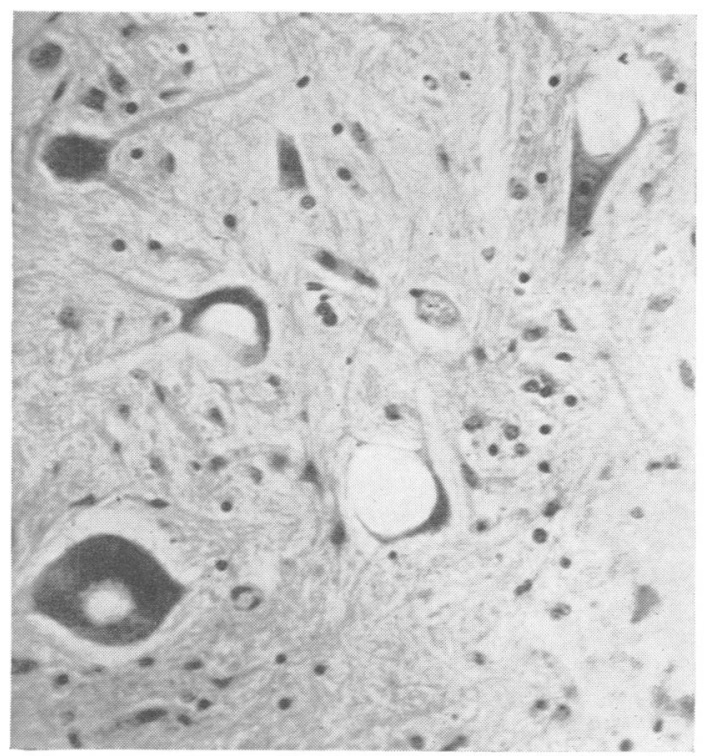

FIG. 13a

Examination of the brain and spinal cord in the two severely affected animals has only shown changes in the nerve cells which have hitherto been regarded as characteristic of scrapie (Zlotnik and Stamp, 1962). Numerous nerve cells greatly distended by single or multiple vacuoles were found in the spinal cord and brain-stem. A few were seen in the thalamus. A coarse fibrous gliosis was present in the grey matter of the spinal cord, and there was also an increase in fibrous neuroglial fibres in the white matter of the cerebellum. The system-like ponto-cerebellar atrophy described by Beck, Daniel, and Parry (1962) as characteristic of scrapie in sheep was not present in these brains. There was no evidence of inflammatory or demyelinating changes. Control animals which had been injected intracerebrally with normal human brain from an accident case remained healthy.

The simplest explanation of this surprising observation is that the sheep were already infected by scrapie at the time of the intracerebral injection, since it is well established that this disease has a long incubation period. We hesitate to accept this hypothesis for the following reasons. Endemic scrapie is found only in the northern part of Iceland and Dr. Pálsson took the strictest precautions to avoid extraneous infection. None of the control animals was affected. It can scarcely be a coincidence that in a previous experiment at the Keldur Institute similar results were obtained in sheep injected with neural material coming from a case of acute disseminated sclerosis. This was kindly sent to us by Dr. Henry

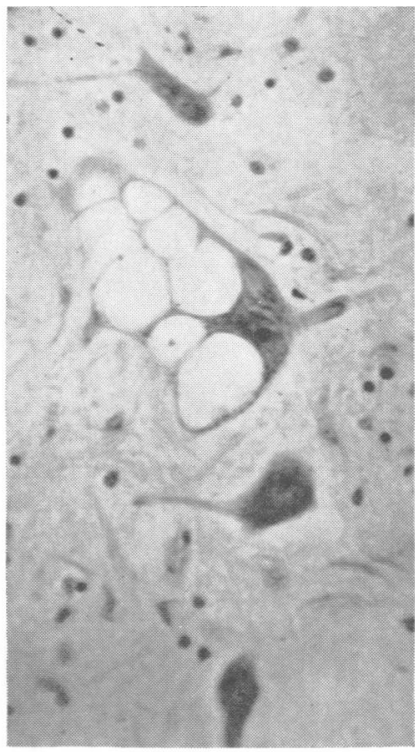

FIGS. 13a and 13b. Sheep. Vacuolated nerve cells in anterior horn of spinal cord. Cresyl violet $\times 240$.

FIG. $13 b$

Miller and the neuropathological report on the human brain has been published by Field, Miller, and Russell (1962). All four of these injected sheep died from a neurological illness closely resembling that reported in this paper, and we have seen the same type of gliosis and vacuolated nerve cells in two of these brains which were examined in this laboratory. As in the present experiment, none of the control animals became ill. At this stage of the work we are unable to offer an explanation for these findings but believe that they are sufficiently remarkable to justify further investigations.

\section{SUMMARY}

The clinical and pathological findings have been described in a case of subacute encephalitis of unknown aetiology. The patient was a woman aged 38 years whose illness lasted 10 months and was characterized by progressive spasticity, ataxia, cranial nerve palsies, and sensory disturbances of posterior column type. Examination of the brain showed lymphocytic cuffing of vessels and microglial proliferation appropriate to a virus encephalitis. In the cerebral cortex these changes were mainly confined bilaterally to the hippocampus, walls of the Sylvian fissure, and basal parts of the frontal lobe. Fibrous gliosis was present in the terminal parts of both optic radiations, one of which was demyelinated. In the cerebellum there were mild inflammatory changes in the dentate nuclei and slight diffuse demyelination and gliosis in parts of the central white matter. 
Extensive encephalitis was present in the basal ganglia and brain-stem. There was massive loss of myelinated axons throughout the posterior half of the spinal cord, accompanied by accumulations of fat granule cells. The grey matter of the cord showed cuffing of vessels and diffuse or nodular microgliosis and there were inflammatory changes in the nerve roots. No inclusion bodies were found.

Material taken from the nervous system at necropsy was injected intracerebrally into four Icelandic sheep. After an interval of two to three years three animals developed a neurological illness which progressed to a fatal termination in two. Examination of the brain and cord in the latter animals has shown vacuolated nerve cells typical of scrapie but no encephalitis or demyelination.

We are greatly indebted to Dr. P. A. Pálsson for his cooperation, and wish to thank the Multiple Sclerosis Society of Great Britain for the grant they have made in support of the experimental work being carried out at the Keldur Institute.

\section{REFERENCES}

Beck, E., Daniel, P. M., and Parry, H. B. (1962). Proc. 4th international Congress of Neuropathology, 1961, Munich, vol. 3, p. 269. Thieme, Stuttgart.

Brierley, J. B., Corsellis, J. A. N., Hierons, R., and Nevin, S. (1960). Brain, 83, 357.

Field, E. J., Miller, H., and Russell, D. S. (1962). J. clin. Path., 15, 278.

Guazzi, G. C. (1961). In Encephalitides; Proceedings of a Symposium, Antwerp, 1959, edited by L. van Bogaert, J. Radermecker, J. Hozay, and A. Lowenthal, p. 470. Elsevier, Amsterdam.

Kalm, H. (1952). Dtsch. Z. Nervenheilk., 169, 89.

Krücke, W. (1957). Nervenarzt, 28, 289.

Lorand, B., Nagy, T., and Tariska, S. (1962). Wld. Neurol., 3, 376.

Macken, J., and Lhermitte, F. (1950). Bull. Acad. roy. Méd. Belg., 6 ser, 15, 205.

Martin, F., and Isler, W. (1957). Schweiz. Arch. Neurol. Psychiat., 79, 73.

Pette, H., and Döring, G. (1939). Dtsch. Z. Nervenheilk., 149, 7.

Tariska, S. (1961). In Encephalitides, edited by L. van Bogaert, J. Radermecker, J. Hozay, and A. Lowenthal, p. 541. Elsevier, Amsterdam.

van Bogaert, L. (1952). Rev. Neurol., 87, 1

(1957). Wien. Z. Nervenheilk., 13, 185.

- (1958). In O. Lubarsch, F. Henke, and R. Rössle: Handbuch der speziellen pathologischen Anatomie und Histologie, vol. 13, pt. 2 p. 394. Springer, Berlin.

Wender, M. (1957). Rev. neurol., 97, 285

Zlotnik, I. . and Stamp, J. T. (1962). Proc. 4th international Congress of Neuropathology, 1961, Munich. vol. 3, p. 468. Thieme, Stuttgart. 